\title{
Twierdza Kłodzko - jako integralny element struktury miasta
}

\author{
Piotr Gleń \\ Samodzielna Pracownia Architektoniczna, Wydziat Budownictwa i Architektury, \\ Politechnika Lubelska, e-mail: p.glen@pollub.pl
}

\begin{abstract}
Streszczenie: W niniejszym artykule przedstawione zostało znaczenie historycznego elementu w strukturze miasta jakim jest Twierdza Kłodzko. Ten górujący nad miastem obiekt militarny stanowi ważną dominantę znajdującą się w centrum Kłodzka. Autor powołując się na analizy oraz badania przeprowadzane przez niego na terenie samej Twierdzy przybliżając możliwości wykorzystania potencjału adaptacyjnego tego miejsca. Obiekt ten pełniący niegdyś znaczącą funkcje militarną powinien w dzisiejszych czasach mieć zupełnie nowe zastosowanie. Prezentując również przykłady adaptacji tego typu obiektów z kraju oraz ze świata przedstawiony został potencjał kulturowy oraz ekonomiczny dla regionu. Obiekty niespełniające swojej docelowej funkcji popadają w ruinę zatracając wartości oraz potencjał w nich ukryty. Możliwości adaptacyjne jakie posiada Twierdza Kłodzko pozwalają na wprowadzenie do niej różnego rodzaju funkcji co skutkować może wzbogaceniem jej wartości. Nadanie współczesnej funkcji w obiekcie zlokalizowanym w centrum kotliny Kłodzkiej stanowić ma element dodany, czyli efekt synergii dla miasta oraz obszaru w którym się ona znajduję. Bazując na opracowanych przez autora materiałach przedstawiony jest potencjał miejsca jako obiektu atrakcyjnego komercyjnie oraz kulturowo. Prezentując sposoby adaptacyjne zwraca się równocześnie uwagę na zagrożenia wiążące się z pozostawieniem Twierdzy działaniom niszczącym.
\end{abstract}

Słowa kluczowe: Twierdza, Kłodzko, synergia, fortyfikacja, adaptacja.

\section{Wstęp}

Fortyfikacje europejskie wchodzą w dziedzinę budownictwa zwaną Architectura militaris. Obecnie traktowane są one jako element dziedzictwa kultury „(...) wszelkie budowle, formy ziemne, zieleń, przeszkody i przekształcenia stosunków wodnych wykonane przez człowieka dla obrony przed atakiem nieprzyjaciela, niezależnie od tego czy jest to fortyfikacja stała, pótstała czy polowa. (...) Przez fortyfikację historyczną rozumie się obiekty wzniesione od zarania dziejów do mniej więcej roku 1957.” [1]. Uwarunkowania geograficzne oraz historyczne terenów Polski spowodowały, iż na obszarze kraju znajduje się bardzo duża liczna obiektów architektury obronnej. , $W$ ostatnim pięcioleciu XX w. podjęto próbę udokumentowania zasobu tych zabytków na obszarze kraju. W efekcie studiów prowadzonych w kilku ośrodkach naukowych przy wspótudziale Towarzystwa Przyjaciót Fortyfikacji, w ramach Krajowego Programu Ministerstwa Kultury i Sztuki ,Ochrona i Konserwacja Architektury Obronnej” (1997-1999) zasoby zachowanych budowli zostały zidentyfikowane i udokumentowane (...). W efekcie projektu badawczego (...) zarejestrowano 4817 zachowanych dzieł obronnych (...), z których prawie wszystkie skupione są w 130 zespołach.” [2]. Obiekty militarne ze względu na swoją funkcję znacząco definiowały strukturę obszaru, w których się znajdowały. Twierdza Kłodzko dzięki naturalnemu zróżnicowaniu terenu stanowi charakterystyczny element 
w strukturze tego miasta. Dominanta architektoniczna oraz terenowa jaką jest ten obiekt miała na przestrzeni lat fundamentalny wpływ na układ urbanistyczny Kłodzka. Obecnie dzięki stopniowi zachowania posiada ogromne wartości historyczne i kulturowe a z punktu widzenia regionu jest to obiekt o dużym znaczeniu turystycznym. Dlatego też autor tekstu zaznacza, iż bardzo ważnym elementem wiążącym te wszystkie aspekty jest należyta dbałość o tej klasy zabytek za czym idzie wzrost turystki i rozwój ekonomiczny regionu. Lokalizacja w centrum Kotliny Kłodzkiej sprawia, że miasto stanowi swego rodzaju węzeł scalający główne miejsca turystyczne w regionie. Jest ono również kontynuacją pasa umocnień Twierdz Sudeckich.

\section{Rys historyczny Twierdzy Kłodzko}

Miasto Kłodzko położone jest w województwie dolnośląskim, w powiecie kłodzkim w północno - wschodniej części Kotliny Kłodzkiej (Rys. 1). Rozwój miasta związany jest z położeniem w dolinie rzeki Nysa Kłodzka. W miejscu ówcześnie znajdującej się twierdzy istniał w XIV w. średniowieczny zamek, który następnie w XVI w. został przebudowany $[3,4]$. W układ urbanistyczny zamku wchodził zespół budynków wraz z dziedzińcami na nieregularnym planie. Ze względu na kształt wzgórza, na którym znajdował się zamek układ przestrzenny opierał się na kaskadowym założeniu przestrzennym. W roku 1622 miasto znajdowało się pod oblężeniem połączonym $\mathrm{z}$ atakiem artyleryjskim, które spowodowało w konsekwencji prace nad modernizacją umocnień oraz samego zamku [5]. Przebudowa zamku zaczęła się dopiero po zdobyciu go przez Fryderyka II. Za modernizację zamku odpowiadał wówczas gen. Gerhard Korneliusz Walrave. W tym okresie powstał nowy plan umocnień a także stworzenie nowego fortu Owcza Góra na sąsiednim wzgórzu [6]. Na przestrzeni lat zmieniał się kształt i struktura bryły ze względu na zmieniające się potrzeby obronne fortyfikacji. Po przejęciu twierdzy przez Austriaków w 1760 r. powstał „Donjon” (ostatnia linia obrony). W kolejnych latach rozwój militarny następował tak szybko, że twierdza przestawała mieć znaczenie militarne. W okresie II Wojny Światowej przeznaczono ją pod kwaterę SS oraz więzienie [7]. Na przestrzeni kolejnych lat nieustannie szukano dla Twierdzy nowej funkcji. W 1944 r. powstała tam fabryka zbrojeniowa AEG z Łodzi [8]. Następnie do 1957 r. obiekt znalazł się w posiadaniu stacjonującego tam lokalnego wojska. Kolejne lata przeznaczono pod działalność gospodarczą taką jak np. przetwórnię wina [9]. W roku 1960 został wpisany do rejestru zabytków i udostępniony na cele turystyczne [10].

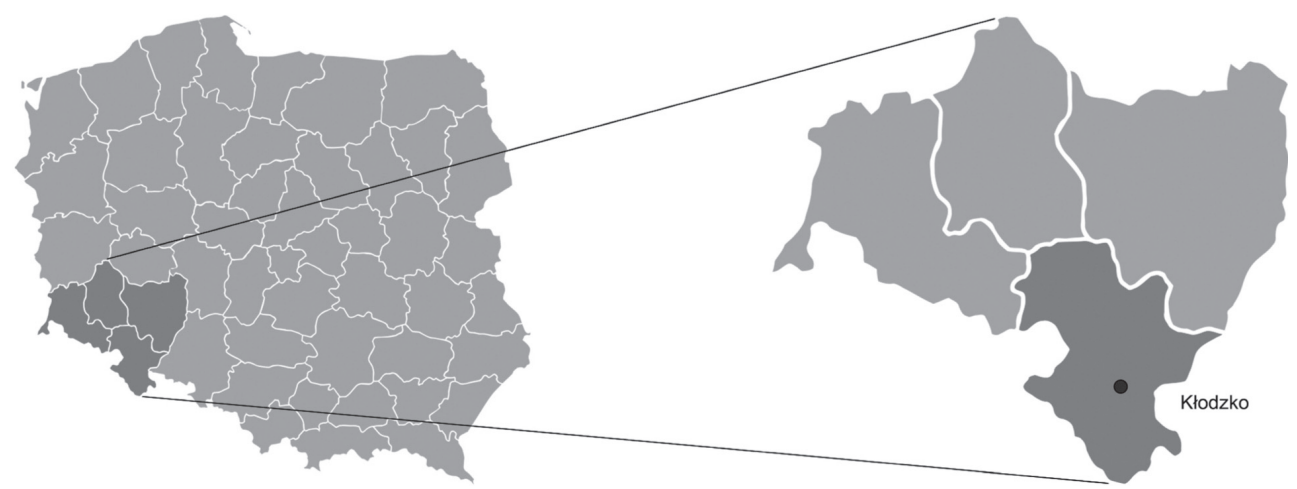

Rys. 1. Lokalizacja miasta Kłodzko - opracowanie autor 


\section{Struktura Twierdzy}

Twierdza Kłodzka jest to obiekt będący systemem obronnym z okresu XVII i XVIII wieku. Dzięki położeniu geograficznemu jest ona przykładem kontynuacji umocnień pasa Twierdz Sudeckich [11]. Sama Twierdza a także towarzyszący jej fort Owcza Góra są swego rodzaju zamknięciem przejścia rzeki Nysa Kłodzka. Dzięki posadowieniu tego obiektu na stromych zboczach możliwe było stworzenie naturalnej bramy na historycznej trasie prowadzącej z Pragi do Wrocławia.

Na strukturę przestrzenną kształtowaną przez zespół obiektów fortyfikacyjnych w Kłodzku składają się elementy urbanistyczne takie jak:

- Twierdza Główna

- Fortyfikacje miejskie

- Fort Owcza Góra

- Obóz warowny w części południowej

Oprócz tych dominujących w przestrzeni należy wyróżnić również pomniejsze obiekty wchodzące w skład założenia fortyfikacyjnego: zespoły koszar, magazyny, śluzy oraz mosty.

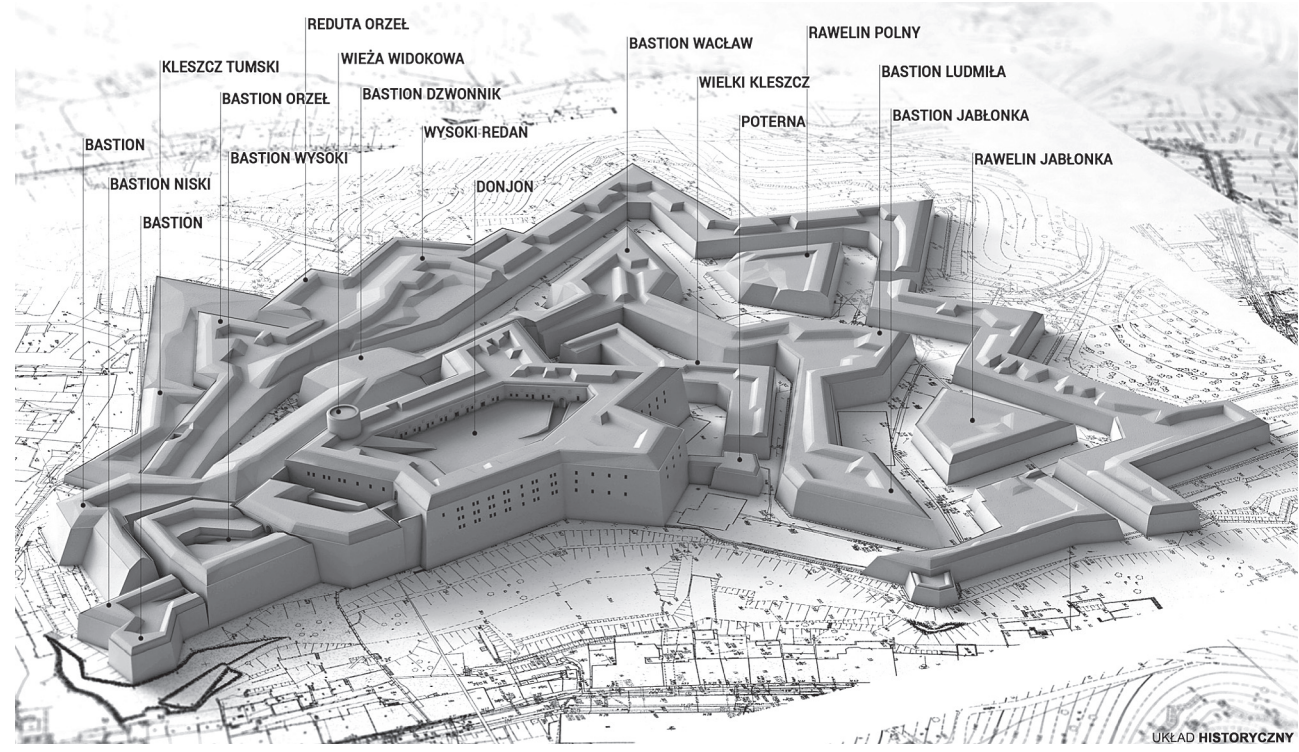

Rys. 2. Schemat struktury Twierdzy Kłodzko - opracowanie Katarzyna Drobek, Katarzyna Tkaczyk, Karol Knap

Sam obiekt Twierdzy Kłodzkiej składa się z elementów takich jak (Rys. 2):

- Donjon

- Wieża widokowa

- Wielki kleszcz

- Poternabastion Jabłonka

- Bastion Ludmiła

- Bastion Wacław

- Bastion Dzwonnik

- Bastion Wysoki 
- Bastion Niski

- Bastion Orzeł

- Kleszcz Tumski

- Reduta Orzeł

- Rawelin Polny

- Rawelin Jabłonka

\section{Agresywna forma a kontekst przestrzenny}

Omawiana w tekście Twierdza Główna jest jednym z najbardziej wartościowych zespołów fortyfikacji z przełomu XVII-XVIII wieku w Polsce. Do początku lat 40 zachowała się ona praktycznie w niezmienionym stanie. Jak zauważył dr Małachowicz w tekście dotyczącym Fortecznych parków Kulturowych ,, Widoczne szkody powstałe głównie w okresie powojennym na skutek gospodarki użytkujacych je instytucji oraz w mniejszym stopniu na skutek zaniedbań konserwacji, głównie roślinności” [12]. Niewątpliwie obiekt ten stanowi element charakterystyczny dla miasta (Rys. 3).

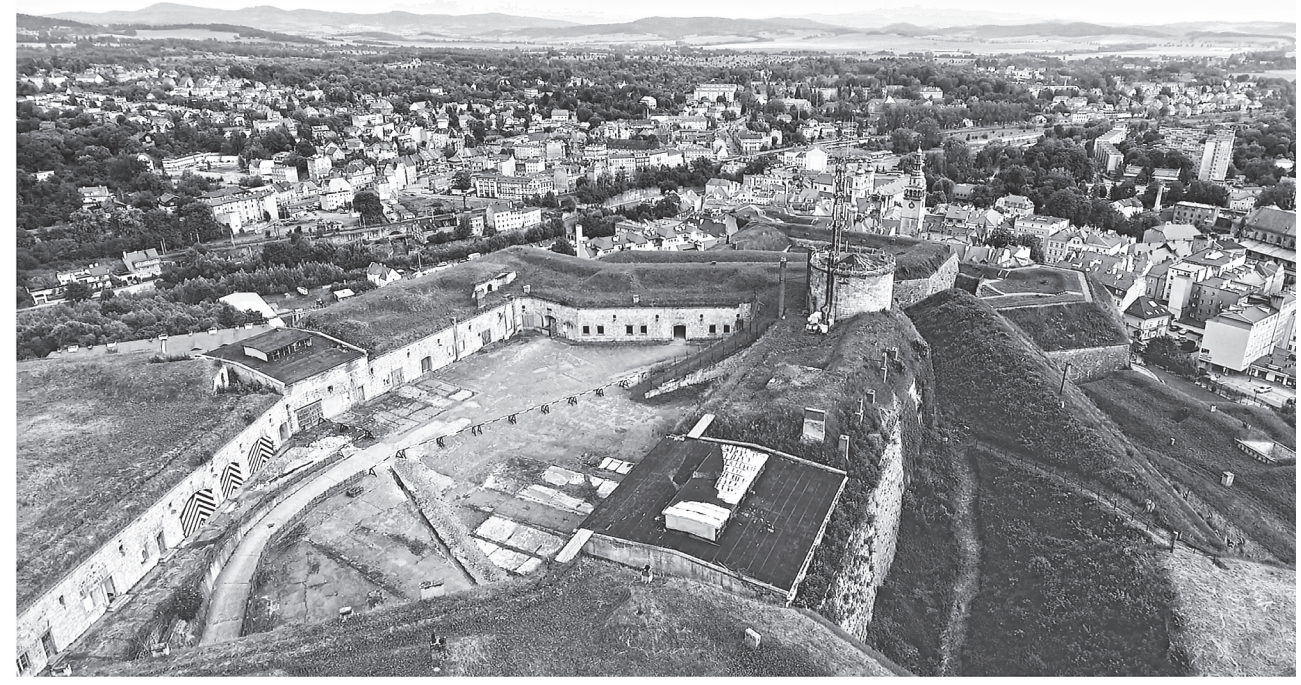

Rys. 3. Widok z lotu ptaka Twierdzy Kłodzko na tle miasta - opracowanie autor

Zarówno jego skala jak również położenie na wzniesieniu powoduje iż stał się on budowlą kształtującą jednocześnie układ przestrzenny wokół siebie (Rys. 4). Relacja przestrzenna pomiędzy Twierdzą a miastem jest ze sobą ściśle powiązana. Opracowany Schwarz plan obrazuje rozmieszczenie zabudowy w mieście, w której niezaprzeczalnie dominantą przestrzenną jest Twierdza Główna. Widoczne są tu również powiązania komunikacyjne prowadzące promieniście od strony omawianego obiektu w kierunku dawnego przedpola a obecnie przez miasto leżące u jego podnóża. Rozmieszczenie w ten sposób ciągów komunikacyjnych definiuje tym samym układ przestrzenny całego miasta. Ma na to wpływ również zróżnicowanie terenu otaczającego Twierdzę Główną oraz rzeka Nysa Kłodzka przepływająca przez miasto. 
Tego typu wartościowy obiekt staje się więc swoistym miejscem węzłowym zarówno dla samego miasta ale również dla całego regionu. Omawiana fortyfikacja stanowi oprócz wartości zabytkowej bardzo atrakcyjne turystycznie miejsce przyciągające ludzi a tym samym napędzające gospodarkę oraz rozwój miasta Kłodzko. Potrzebna jest świadomość, iż obecna funkcja nie jest skazana wyłącznie pod przeznaczenie obiektu muzealnego. Należy poszukiwać nowych odważnych rozwiązań związanych z adaptacją [13]. Czasem ważnym jest zrozumienie potrzeby społecznej i ekonomicznej w pozyskiwaniu przyszłego inwestora dla tak nietypowych budowli [14]. Będzie miało to ogromny wpływ na dalsze istnienie (w tej lub innej formie) obiektu, które ściśle powiązane jest z funkcjonowaniem i rozwojem przestrzennym jak również ekonomicznym czy kulturowym miasta.

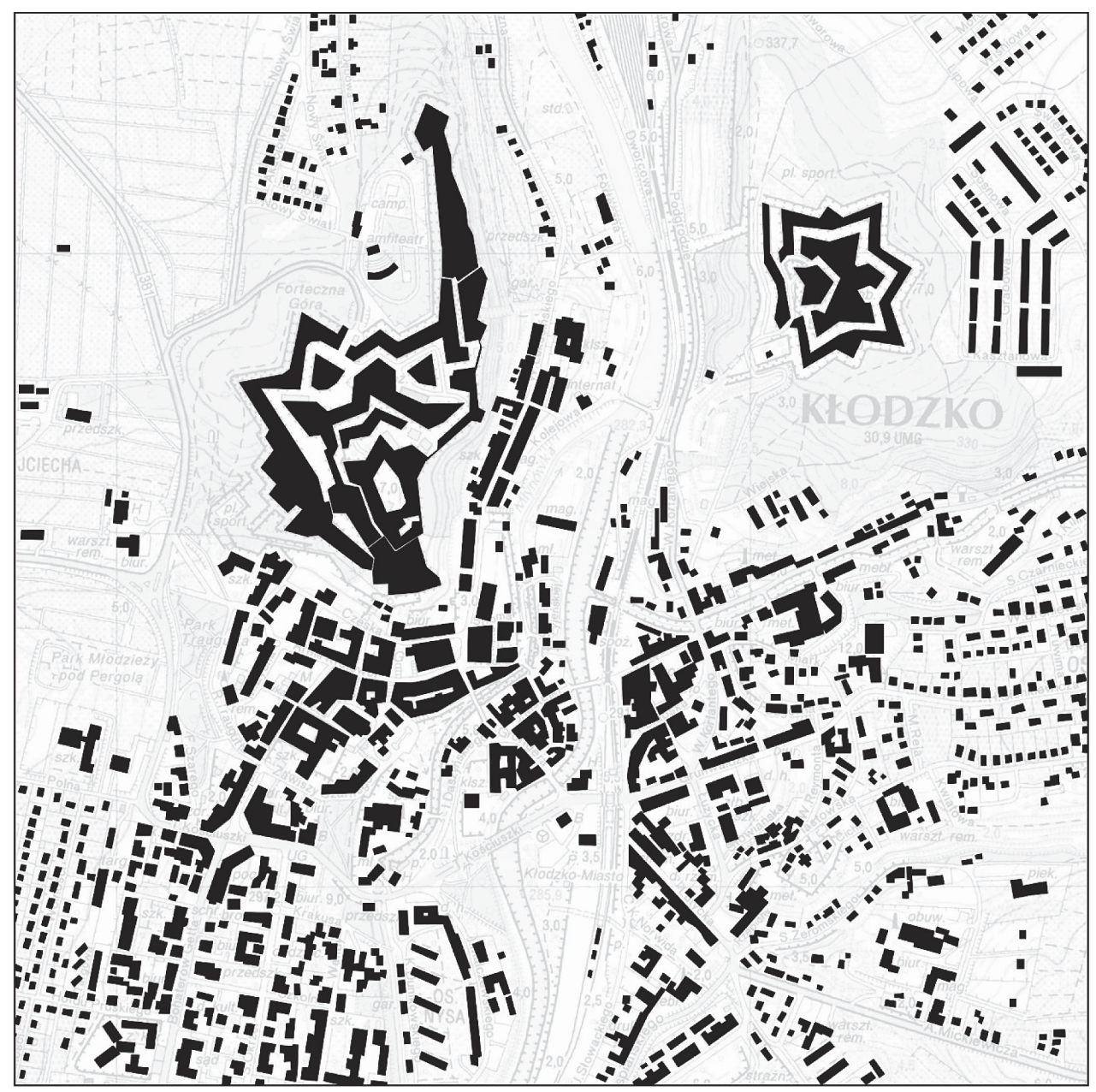

Rys. 4. Analiza kompozycyjna - opracowanie Katarzyna Drobek, Katarzyna Tkaczyk, Karol Knap

Ważnym elementem mówiącym o oddziaływaniu tej fortyfikacji jest aspekt turystyczny. Pierwotne obronne przeznaczenie od dawna nie jest już aktualne ze względu na dynamicznie postępujący rozwój militarny na świecie. Obecnie budowle tego typu pełnią wyłącznie 
funkcję atrakcji turystycznej co w konsekwencji odnosi się do kształtowania okolicznych układów urbanistycznych. Miasta znajdujące się przy tego typu zabudowaniach zaczynają nastawiać swoją gospodarkę (a tym samym ma to wpływ na ich strukturę przestrzenną jak i w konsekwencji na ich urbanistykę) na zwiększającą się liczbę turystów. Powstają ośrodki zapewniające nocleg w mieście dla osób przyjezdnych. Tym samym skutkuje to rozwojem ośrodków gastronomicznych w mieście i jego okolicy. Kontynuując tą myśl jednoznacznym staje się, iż w konsekwencji wzrostu osób przyjezdnych (tymczasowo w celu zwiedzenia Twierdzy Kłodzko) zwiększa się ruch samochodowy w mieście. Powstaje tym samym potrzeba komunikacji a więc zmiany organizacji przestrzennej wewnątrz tkanki miejskiej. W skutek zwiększenia ruchu kołowego logicznym staje się potrzeba wprowadzania publicznych parkingów. W efekcie skutkuje to zmianami w kształtowaniu się układu przestrzennego współczesnego miasta.

\section{Wnioski}

Wzrost osób przyjezdnych spowodowany atrakcyjnością turystyczną Twierdzy Kłodzkiej skutkuje zmianami w pierwotnym układzie urbanistycznym tego miasta. Zwiększenie się liczby osób odwiedzających miasto wymusza potrzebę zapewnienia im punktów obsługujących. Tego typu punkty można określić mianem satelitów uzupełniających centralny element jakim jest Twierdza Kłodzko. Mowa tutaj m. in. o hotelach, restauracjach, sklepach z pamiątkami, budynkach potrzebnych do obsługi administracyjnej obiektu czy chociażby parkingach.

Podsumowując autor tekstu pragnie zwrócić uwagę na bardzo ważny aspekt obiektów zabytkowych na przykładzie Twierdzy Kłodzko w kontekście zależności w/w twierdzy a elementami niewchodzącymi w skład zabytkowej tkani - satelitami obiektu.

Ważne jest więc nadanie historycznej dominującej formie odpowiedniej współczesnej funkcji rozważając szerszy kontekst oddziaływania na układ urbanistyczny w którym się on znajduje. Relacja ta jest ściśle ze sobą powiązana i odziaływująca na siebie wzajemnie.

\section{Literatura}

[1] Gruszecki A. Specyfikacja zasobów architektury obronnej w Polsce, ich ochrony i zagospodarowania [w:] M. L. Lewicka [red.], Ochrona zabytków architektury obronnej, Giżycko 1997 r., s. 19.

[2] Kartograficzne udokumentowanie zasobów budownictwa obronnego w Polsce. Polowa XVIII w. -XX w., projekt badawczy KBN nr 7T07F03610, praca zbiorowa pod kier. A. Gruszeckiego, Warszawa $2007 \mathrm{r}$.

[3] Guerquin B. Zamki Śląskie 1957.

[4] Broniewski T. Śląsk w zabytkach sztuki 1963.

[5] Triller E. Rocznik Ziemi Kłodzkiej 1958 T.III 1959.

[6] Bukal G. Niderlandyzm w sztuce polskiej 2000.

[7] Jędrysiak T., Mikos von Rohrscheidt A. Militarna turystyka kulturowa PWE, 2011.

[8] www.dawnekłodzko.pl, data odczytu: 26.03.2018.

[9] www.zamkipolskie.pl, data odczytu: 26.03.2018.

[10] Decyzja KL-V-1/61/30 z 13 maja 1960 r. dot. wpisu do rejestru zabytków.

[11] Bukal G. Twierdza kłodzka 1620-1900 [w:] Kwartalnik Architektury i Urbanistyki, XXXI (3-4) (1986). 
[12] Małachowicz M. Kłodzko - Forteczny Park Kulturowy [w:] M. L. Lewicka - Cempa [red.], Nowożytne fortyfikacje śląska. Twierdze Kłodzko i Srebrna Góra, Fortyfikacja tom XII Warszawa 2000, s.58.

[13] Jarocka-Mikrut A., Glen P. The Problems of Eastern Orthodox Church Buildings of Historical Value - Changing Uses over the Years. Civil And Environmental Engineering Reports 21(2) (2016) 32.

[14] Gleń P., Jarocka-Mikrut A. Adaptation of forgotten buildings the example of the ruins of the Kościelec Protestant Church in Piaski. Civil And Environmental Engineering Reports 19(4) (2015) 14.

\title{
Kłodzko Fortress - as an integral element of the city structure
}

\author{
Piotr Gleń \\ Independent Architectural Workshop, Lublin University of Technology, \\ Faculty of Civil Engineering and Architecture, e-mail: p.glen@pollub.pl
}

\begin{abstract}
This article presents the importance of a historical element in the city structure which is the Kłodzko Fortress. This towering military building is an important dominant located in the center of Kłodzko. The author citing the analyzes and research carried out by him in the territory of the Twierdza, bringing closer the possibilities of using the adaptive potential of this place. This object, once performing a significant military function, should now have a completely new application. Also presenting the examples of adaptation of this type of objects from the country and the world, the cultural and economic potential for the region has been presented. Objects that do not fulfill their target function fall into ruin, losing values and potential hidden in them. The adaptive possibilities of the Kłodzko Fortress allow for the introduction of various functions to it, which may result in an enrichment of its value. Giving a contemporary function in a facility located in the center of the Kłodzko valley is to have an added element, i.e. a synergy effect for the city and the area in which it is located. Based on the materials developed by the author, the potential of the place is presented as an attractive commercial and cultural object. Presenting adaptation methods, at the same time, attention is paid to the risks associated with leaving the Fortress to destructive activities.
\end{abstract}

Keywords: Fortress, Kłodzko, synergy, fortification, adaptation. 
